\title{
Study on Hotel Technical Talents Based on Modern Management
}

\author{
Haiyan Yu \\ Chongqing Vocational Institute of Engineering \\ Chongqing,China 402260
}

\section{Keywords: Modern management; Hotel; Technical personnel}

\begin{abstract}
The promotion of the quality of service requirements results in the hotel technical skilled personnel requirements will also be improved, and with the modern management mode, personnel training has been greatly changed. This paper starts with the necessity of training technical talents in hotels, and briefly studies the existing problems and how to train technical talents in the modern management mode.

In modern society, with people's consumption level rising, the product quality requirements are also rising, but the concept of product quality performance advantage is no longer limited to the product itself, the extension of the value and service have become part of the product quality. Among them, the quality of service has become an important factor in determining the choice of people's consumption. In the background of the increasingly fierce market competition, the hotel service quality is active or passive, and cultivating technical talents has become a pressing matter of the moment for the hotel enterprises.
\end{abstract}

\section{Necessity for Hotels to Train Skilled Personnel}

No matter what the economic background or political background, personnel are scarce social resources, and talent determines whether an enterprise has the strength and competitiveness, and all the business activities of enterprises and the profit rely on talent and high technology talents to support, so not only the wine shop needs to cultivate technical talents, all enterprises and institutions need to maintain the rapid development of society of cultivating technical talents.

Necessity of the development of Education. From the perspective of education, China's Ministry of education as makes professional hotel management a pilot in Colleges and universities in the establishment of hotel management specialty in China was first established in Guangdong University of Business in 2006, and until 2013, a nationwide university hotel management is only 35.[1] It is because of the late start and the relatively slow development, China's colleges and universities in the hotel management professional personnel training mechanism is not fully developed, and the training mode and method is relatively scarce, and the content of the curriculum setting is not reasonable, so the discipline development, it is necessary and urgent to maintain education to adapt the development of the industry with the trend of training technical personnel.

Necessary requirements for the development of the industry. Mentioned above from the perspective of education, training technical personnel maintains education to adapt to the development trend of the industry, while from the perspective of the development of the industry, China's hotel industry is the current group, the scale of the development trend, the rapid development of industry is the opposite side. [2]According to incomplete statistics, the increase of average annual demand for talent of the hotel industry is far more than the number of related personnel employment increase. However, the demand for diversified talents in hotels requires the cultivation of diversified technical talents to maintain the normal operation of the hotel enterprises and the sustainable development of enterprises and industries.[3]

Necessary requirements of social development. The rapid development of the hotel industry, on the one hand shows the rigid demand of the industry, and on the other hand, it shows the rapid development of the society. The hotel industry needs to understand business, understand the management and high correspondence and industry technical personnel to support the development of the industry, whether it is a part of social development, all belong to the development of education or hotel industry. Therefore, from the perspective of social development, it is also one of 
the hotel culture technology providing the source power for the long-term healthy development of the society economy and education.[4]

\section{Main Problems Existing in the Training of Technical Talents in Hotels}

Although the rapid development of the hotel industry for both inside and outside of the industry are beginning to focus on the training of technical personnel, but due to the short time of development, lack of research on the training mode of foreign talents management, the reason about few knowledge of the local economic and political environment leads to training technical personnel for the hotel's domestic problems still exist to be solved, which mainly including the following aspects:

Lack of professional training. One of the important sources of hotel technical personnel is professional training colleges, but at present, our country's college management and other related professional training for technical personnel of a hotel is the lack of a mature professional training system, the existing hotel management course system is borrowed from the courses of tourism management, and have not formed a set to conform to the characteristics of the hotel industry the curriculum system, which can not reflect the characteristics of the subject, and it unable to meet the needs of the industry and the market; the second is the lack of high quality teachers, the general university hotel management professional teachers is from tourism management or other professional into the hotel management experience which is almost zero, even if the previous advanced hotel management experience is also difficult to maintain management experience of the industry, although some cooperation between universities and enterprises enable teachers to participate in the hotel management practice, but it does not reach the management of corporate decision-making, and the hotel management's understanding and experience is insufficient; the third is the lack of reasonable and flexible teaching methods, subject to the limitations of traditional teaching method and way of thinking, the existing hotel management teachers are not aware of the theory and practice of hotel management combining the importance of teaching, or do not have the ability to change which has been formed the inertia of the teaching mode.[5]

Inadequate training of hotel enterprises. In addition to professional training colleges, hotel personnel training is also an important channel of hotel technology talents according to their own needs, but the hotel enterprise training mode problem is a lack of advanced management concept, management mechanism of enterprises depends on the enthusiasm of the staff team discipline and team work. If there is not a reasonable employee management mechanism, it unable to play their value, this is the lack of job training; the second is the lack of international talent standard, the ability of hotel management personnel requirements, quality requirements and certification of specialization do not establish an international standard, so the hotel in the training of personnel lack of professional and technical personnel assessment to confirm whether meets the professional standards and requirements; the third is missing post culture consciousness and conditions, on the one hand, intense competition in the market is the result of flow of hotel management personnel which is large, enterprise has more concerns in deciding whether to carry out personnel training, on the other hand, the market for the hotel and technical personnel training institutions are not too mature which achieve positions outside the culture conditions, or related to the human and material resources consumption.[6]

\section{Modern Management of Hotel Technical Personnel Training Measures}

Double lack of training and enterprise culture in higher technology result in the hotel talent scarcity, and the market and social demand for talents has forced the industry to seek measures to solve the problems of talent training, which means only considering the universities, enterprises, social factors, it can study and develop according to the situation of our country and society the market situation and solutions, in general, there are mainly the following several paths:

ICarrying out cooperation between schools and enterprises and implement the training mode of "dual subject". Hotel training technical personnel needs professional theoretical knowledge as the basis, and it also needs practical experience to improve the overall quality, so take 
the knowledge of the model helps to improve the students' combination of theory and practice of the cooperation between universities and enterprises culture. On the one hand, through the university curriculum design optimization, teaching method innovation, teaching equipment and facilities of the first evolution of teaching management, strengthen measures to actively play school teachers in technical personnel training on the subject; on the other hand, the hotel enterprises carries out the training base construction and design related courses allowing students to participate in business with the management process of the hotel and learn the relevant experience, which plays the main body of the hotel in the technical personnel training on the role, at the same time, the hotel can also through the practical activities and operation of selecting students to become the enterprise employees, and the solution not only solve the hotel enterprise demand for technical talents, and makes contributions to the employment rate of college.[7]

With the vocational education system, carrying out "multi-level"training mode. The train of hotel management and technical personnel is not overnight work, according to different students the staff ability and personalities, or training of the main economic conditions, different environmental conditions and objective demand, it should adopt the "multi-level" training mode. On the one hand, from the perspective of professional education, it can be combined with the entrance way into the "higher vocational college-undergraduate college-professional master-doctor" level and stage of culture; on the other hand, from the angle of occupation training, it can be divided into "intern management line-management trainee- management post" stage of training. Among them, the training mode of the two angles can be integrated with each other, so as to form a scientific and flexible "multi-level" training mode.[8]

Using international exchange platform, integrating domestic and international advanced experience. With the further opening up of the country, the increase in the number of people traveling abroad at the same time, with long history, vast territory and abundant resources, China also attracts people from all over the world, while the establishment of the discipline of the hotel management major in China started late, but this does not prevent us from using the international exchange platform or directly to visit and study abroad, their advanced management business and personnel training idea and means. On the one hand, it can through academic exchanges providing students and exchange opportunities which leads to the students direct transnational learning and communication; on the other hand, hotel enterprises can also hire foreign experience in hotel management and personnel training management personnel to help the operation and management of enterprises, but also can help the hotel staff to learn and improve themselves. In addition, it also can let teachers or hotel domestic enterprise training personnel going abroad, learning exchanges, cutting-edge knowledge will be back home, and according to the domestic market environment and the enterprise's own situation, to build the training system of technical talents with strong adaptability.[9]

Improving training methods, stimulating students and employees' creative thinking. Generally speaking, universities teachers on hotel management teaching will contact materials and combined with his own subjective experience of teaching, this way has some scientific, but largely confine their thinking mode, in some teaching methods, in principle, it is guided by teachers and students or employees as the main body, but affected by the traditional way of teaching, while teachers or trainers usually ignore this point. In the process of teaching, it not only need to add interactive elements, but to let more students and employees to learn by doing, through develop the habit of independent thinking to solve some of the problems, and for some beginners not professional idea not to interrupt and negative rather than through the case and they analyzed, and lead to the growth by their own. [10]In the long run, improving their confidence and creativity will not only help their career in the future, but also contribute to the development of the hotel industry.

\section{Conclusion}

Modern management emphasizes the innovation of management concept, management mode innovation and continuously upgrade the level of management, hotel training technical talents based on modern management should first clear the concept of training, and with the training mode of the 
introduction of cutting-edge combined with multi-channels of cultivating talent development path, positive progress and innovation consciousness to improve the service level of the enterprise in order to cultivate the market to meet the needs of the society and the hotel industry technical personnel.

\section{Reference}

[1] Zhijun Fan, Anguo Du.Discussion on current situation and implementation path of talent training mode of hotel management specialty in Higher Vocational Colleges[J].Journal of Hebei Vocational College,2012 (01) : 91 - 94.

[2] Ruitian Li.Research on training model of hotel management skill based on market demand[D].Ocean University of China, 2014.

[3] Xueying Liu.Research on Hotel Talent Training Mode from the perspective of school enterprise cooperation[D].Central South University, 2014.

[4] on hotel financial risk prevention [J]. Wang Bin. Modern business. 2016 (27)

[5] Liu Guangrong.Hotel development strategy in network era [J]. Travel overview (second half). 2014 (10)

[6] Chen ting.A study on the Countermeasures of staff turnover in hotels [J]. Shopping mall modernization. 2014 (31)

[7] research on the management of The Contemporary Hotel operation cost [J]. Li Dexin. Management. 2014 (09)

[8] Research and Exploration on cost management of [8] Hotel [J]. Li Zhen. Modern economic information. 2014 (10)

[9] analysis of hotel internal accounting control, [J]., Shuang Shuang. Management. 2013 (30)

[10] management cost management of state owned hotels [J]. Hong Jian. Business. 2013 (04)

[11] About our CNKI honor copyright notice customer service center 